\title{
A HISTÓRIA DA ORGANIZAÇÃO DO ENSINO PRIMÁRIO DE BELÉM DO PARÁ, 1937 a 1945: AÇÕES E LIMITES ${ }^{1}$.
}

\author{
Maria de Fátima Matos de Sousa \\ Universidade Federal do Oeste do Pará - UFOPA. \\ fmatos@ufpa.br \\ Maria José Aviz do Rosário \\ Instituto de Ciências da Educação -UFPA \\ mrosario@ufpa.br
}

\begin{abstract}
RESUMO
Este artigo é uma aproximação com a discussão, organização e sistematização de fontes que registram a história da educação da Amazônia. Parte da tese de que a organização do ensino primário de Belém do Pará, no período, esteve ligada às diretrizes traçadas nos Regimentos do Ensino Primário Estadual, com forte influência da Secretaria Estadual de Educação. Objetiva disponibilizar documentação referente à história da educação de Belém do Pará, visando minimizar os problemas de acesso às informações, à dispersão, destruição e alienação documental e, refletir sobre o processo de organização do ensino primário, no período. Sua estruturação situa o estudo apresentando à temática e o objeto de estudo, evidencia as principais mediações quando da articulação, elaboração e efetivação do ensino primário, bem como discute as relações existentes entre os poderes políticos instituídos e as reivindicações sociais. Em sua conclusão preliminar,as fontes documentais, apontam a organização do ensino primário, como um instrumento importante de barganha política e que ao mesmo tempo passava por um processo de redirecionamento histórico-políticosocial no qual os poderes políticos estadual e municipal figuravam como atores principais no papel de mediadores e elaboradores das propostas pertinentes à educação.

Palavras-chave: Ensino Primário, Belém do Pará, Organização

\section{THE STORY OF THE ORGANIZATION OF THE PRIMARY EDUCATION OF BELÉM OF PARÁ, FROM 1937 TO 1945: ACTIONS AND LIMITS}

\begin{abstract}
This article is an approach to discussion, organization and systematization of sources that record the history of education in the Amazon. Part of the thesis that the primary organization of Belém of Pará, in the period, was linked to the guidelines set forth in the Rules of Procedure of the State Primary Education, strongly influenced by the state Department of Education. It aims to provide documentation regarding the history of education of Belém of Pará, to minimize problems of access to information, dispersion, destruction and disposal of documents and reflect on the process of organizing primary education in the period. Its structure places the study presented to the subject and the object of study, the main highlights of the joint when mediations, preparation and execution of primary education, as well as discusses the relationship between the powers established political and social demands. In its preliminary, documentary sources, suggest the organization of primary education as an important tool for political bargaining and that while going through a redirection process, political and social history in which the political powers were listed as state and local actors the main role of mediators and makers of proposals relevant to education.
\end{abstract}

Keywords: Primary Education, Belém do Pará, Organization 
A história da organização do ensino público de Belém do Pará, no Século $\mathrm{XX}$, passou por um processo de mudança significativo. A leitura e análise das fontes documentais mostram os vestígios de uma riqueza ímpar. A documentação a respeito dessa trajetória faz o "tempo voltar no tempo". Essa organização, durante o Estado Novo, esteve ligada às diretrizes traçadas nos Regimentos do Ensino Primário estadual e aos encaminhamentos político/pedagógicos da Secretaria Estadual de Educação paraense. A partir de 1949, com a criação de um órgão específico, Diretoria de Ensino Municipal, através da lei $\mathrm{n}^{\circ} 503$ de 27 de maio, para tratar de suas demandas, o ensino primário belenense conseguiu organizar-se com mais autonomia, ainda que limitada as contradições decorrentes da dinâmica social vigente.

Neste artigo pretende-se apresentar e discutir, por meio de fontes históricas, a organização do ensino primário de Belém do Pará, disponibilizar análise da documentação no período, visando minimizar os problemas de acesso às informações, particularmente na questão de dispersão, destruição e alienação documental e refletir sobre o processo de organização do ensino primário, no período e desse modo compreender a movimentação e posicionamento na composição da educação paraense em face do contexto social/político.

Partiu-se do entendimento que o ensino primário de Belém do Pará se constituía num elemento importante, contraditório e complexo para composição de projetos educacionais situados na sociedade belenense.

Belém por ser um importante município do Brasil, e uma das mais belas capitais da Região Norte, era vista como referência para implementação do modelo instaurado que se expressava por meio das intervenções nas instituições sociais, particularmente nas educacionais. No dizer de Reis (1942, p. 171), 'se destaca na eficiência das organizações de assistência pública, deinstrução pública, de segurança e de saúde da população'.

O governo central encontrava na figura dos dirigentes belenenses ressonância aos seus propósitos. A esse respeito é interessante à fala do secretário geral do Estado, Deodoro de Mendonça ${ }^{2}$, no discurso do primeiro aniversário do Estado Novo.

Todo paiz levanta-se hoje para saudar na pessoa do eminente chefe da Nação, o dr. Getúlio Vargas, a passagem do primeiro aniversário do Estado Novo, proclamado pelo seu patriotismo e clarividencia, na hora precisa em que o Brasil se afundava na mais desbordante campanha de separação de segregando os laços preciosos de sua união espiritual em tôrno da Pátria para se deixar conduzir às consequencias de paixões desalmadas $^{3}$ e improfícuas (GOVERNO DO ESTADO DO PARÁ, 1940, p. 4) (grifo nossos).

Os estudiosos ressaltam que os prefeitos $^{4}$ seguiam a linha traçada pelo Estado Novo. A fala sobre Abelardo Leão Condurú, ${ }^{5}$ indicado pelo Interventor José Malcher, é um bom exemplo dessa indicação.

O senhor Abelardo Leão Condurú elemento destacado na sociedade paraense e espírito experimentado em vários setores da vida pública [...]. Inteligente e operoso, testemunha a actividade do estimado prefeito as suas realizações no actual governo, discriminadas no discurso expositivo com a interventoria, por intermédio do secretário geral do Estado, 
Deodoro de Mendonça, deu conta das atividades da administração pública em todos os setores no primeiro aniversário do Estado Novo. (RODRIGUES, 1939, p. 172).

O Prefeito seguia a cartilha do Estado Novo, mas procurava dar um tom próprio ao seu projeto político e de ensino, objetivando orientar e atender as demandas educacionais da sociedade belenense. Desse modo, ao edificar sua obra educacional, participava do grupo dirigente local e ao mesmo tempo fortalecia a sua figura como político de grande influência. Os noticiários da época evidenciam a participação do prefeito nas obras em que a prefeitura estava envolvida.

\section{Noticiário: \\ Ontem, pela manhã, em companhia do Dr. Nilo Bezerra, prefeito municipal de Rio Branco, Território do Acre, o prefeito Abelardo Condurú visitou vários estabelecimentos e instituições do Estado e do Município [...]. \\ [...] Do bairro da Pedreira, dirigiram-se os mesmos ao Grupo escolar Dr. Freitas, cujas obras de reconstrução e ampliação progridem rapidamente. [...], em companhia prefeito Condurú, seguiu para o bairro do Jurunas, onde visitou demoradamente as obras do grupo escolar Camilo Salgado.(DIÁRIO DO ESTADO DO PARÁ, 01/02/1940).}

A construção de escola constituía-se em oportunidade ímpar para a veiculação e consolidação de idéias no campo político. A importância da escola Dr. Freitas pode ser verificada no discurso do Diretor de Educação e cultura:

O grupo escolar 'Dr. Freitas' inaugurado pelo presidente Getúlio Vargas, que é um orgulho da nossa organização de ensino primário, foi reconstruído, ampliado e remodelado, sob directa assistência do prefeito Abelardo Condurú, pelo Departamento de Engenharia Municipal, em estreita cooperação com o governo do Estado (PREFEITURA MUNICIPAL DE BELÉM, 1940, p. 31).

A (in)dependência do prefeito Abelardo Condurú, em 1940, pode ser percebida quando da injeção de recursos aplicados, numa ação conjunta com o governo do Estado para construção de prédios escolares:

Atendendo a que o governo do Estado tenciona construir, no bairro chamado - Cidade Velha - um grupo escolar, concorrendo, deste modo, para dar maior eficiência à instrução da infância neste importante trecho de nossa capital; atendendo a que o edifício que se vai construir objetiva um dos mais importantes postulados do Estado Novo que é, de acôrdo com a Constituição vigente, "assegurar', pela fundação de instituições públicas de ensino em todos os seus gráus a possibilidade da infância e da juventude receberem uma educação adequada às suas faculdades, aptidões e tendências vocacionais;

Atendendo ainda, que a instrução às classes menos favorecidas é o dever daquele que exercita qualquer parcela do poder federal, estadual ou 
municipal, estendendo-se esse dever até os sindicatos e aos particulares como inequívoca demonstração de patriotismo.

RESOLVE:

Ajudar na construção nos termos da lei (DIÁRIO DO PARÁ, 01/03/1940:05).

O poder político, ao empreender ou erigir construções que expressavam a obra educacional de Belém, o fazia porque acreditava na possibilidade de demarcar a presença da prefeitura como co-autora de obras em andamento. Por outro lado, o atendimento às diversas demandas sociais, inclusive aquelas advindas da oposição fazia-se necessário para emoldurar o desenho do quadro político. A educação servia como suporte de atendimento às necessidades da sociedade belenense.

A demonstração de contribuição ao projeto político do governo central pode ser analisada a partir do discurso de inauguração da Escola Dr. Freitas.

Não tínhamos realmente modo mais significativo e patriótico de assinalar às gerações futuras a sua passagem por aqui do que a abertura de mais uma casa de ensino. É dever imperioso salientar que esta significativa construção que obedece aos princípios da pedagogia moderna, é o resultado da alta compreensão que têm de seus deveres os snrs. interventor federal e o prefeito de Belém. (Prefeitura de Belém, 1940:31) (grifos nossos.)

A demarcação política pode ser percebida nas palavras do diretor de educação, Sr. Miguel Pernambuco Filho, entendendo o Grupo Escolar Dr. Freitas como uma obra importante para a viabilidade do projeto político-educacional belenense, em consonância com o governo central, enalteceu a figura do prefeito pela realização da obra.

O Snr. Abelardo Condurú, na qualidade de professor e governador da cidade, teve a perfeita intuição de que os administradores só valem pelas obras que realizam e que todas essas, as que representam maior utilidade são, incontestavelmente, as educacionais. Daí o seu decidido apoio a tudo o que se relaciona com a instrução. Este modelar grupo escolar, construído pelo Estado e pelo Município, é uma admiravel demonstração do espirito de solidariedade que reina na administração paraense (PREFEITURA MUNICIPAL DE BELÉM, 1940, p. 32).

Finalmente, embevecido com obra de tão grande porte para a educação paraense e falando até mesmo pelos anseios da juventude paraense, convida o interventor federal para inaugurá-la.

A mocidade estudiosa do Pará, que confia plenamente em v.ex., pede, por meu intermédio, que lhe conceda a honra de inaugurar este grupo escolar, que ficará como padrão de gloria de uma administração bem intencionada, e simbolizará a esperança de que dentro em breve será realizada por v. ex. a sua maior aspiração: a creação de uma Universidade do Pará6. (Prefeitura Municipal de Belém, 1940, p. 33). 
A íntima ligação do prefeito com dirigentes, denota a ingerência nos negócios e, sobretudo, nos ajustes realizados no interior da sociedade paraense, portanto, belenense. A ingerência nas instituições era de tal magnitude, que os prefeitos ficavam à mercê dos interventores até mesmo para a simples concessão de férias, como é demonstrado através da portaria do governo do Estado, datada de 08 de dezembro de 1943.

Cel, Interventor Federal no Estado, usando de suas atribuições;

RESOLVE:

Conceder ao Sr. Alberto Engelhard, prefeito municipal de Belém, vinte (20) dias de férias regulamentares, de acordo com o artigo $2^{\circ}$ do decreto-lei, $n^{\circ} 4.147$, de 28/10/1942, a contar desta data.

Vale lembrar que os prefeitos eram indicados e nomeados pelos interventores federais, no Estado; assim, não tinham liberdade suficiente para imprimir a sua própria vontade política.

Art. $7^{\circ}$ - O prefeito nomeado livremente pelo Governador do Estado e dependendo directamente deste é o órgão executivo da administração municipal, conforme legalmente prescripta, e a elle cabe cumprir e fazer cumprir toda legislação que, na conformidade da Constituição da República, vigorar em matéria municipal. (GOVERNO DO ESTADO DO PARÁ, 1940, p. 05).

No setor educacional, a ingerência ficou evidenciada quando da reformulação do Regimento do Ensino Primário ${ }^{7}$, em 1943. Ao regulamentar o ensino primário decide também quando e onde os prefeitos municipais poderiam criar escolas sob suas responsabilidade político-administrativas.

Art. 211 - Os prefeitos municipais poderão criar escolas de alfabetização - escolas municipais - onde houverem de 15 a 30 crianças em idade escolar, com gratificações mensais de $\mathrm{Cr} \$ 60,00$ a $\mathrm{Cr} \$ 100,00$, correndo as despezas, cinquenta por cento por conta do Município e cinquenta por cento por conta do Estado. (GOVERNO DO ESTADO DO PARÁ, 1944, p. 98).

Em relação à educação, somente no ano de 1944, a legislação permitiu uma definição mais precisa de como seria encaminhado no Estado o ensino primário público e particular. O público era obrigatório, gratuito e leigo e sua organização compreendia, segundo o Regimento do Ensino Primário (1944, p. 62):

1 - O INFANTIL, ministrado nos cursos de Jardim da Infância às crianças de 0 a 6 anos;

2 - O PRIMÁRIO, ministrado nos seguintes cursos:

a) Integral - distribuído em 5 anos nos grupos escolares;

b) Elementar - ministrado em dois anos, nas escolas reunidas e isoladas e auxiliares suburbanas;

c) Popular - ministrado em dois anos, nas escolas noturnas e nos afastamentos urbanos, nas isoladas e nas auxiliares; 
3 - O ESPECIAL, para débeis orgânicos e retardados pedagógicos. (grifos nossos).

Ainda segundo o Regimento do Ensino Primário (1944, p. 63), ensino primário integral, abrangia um elenco de disciplinas, organizadas da seguinte forma:

Art. $4^{\circ}$ - (...) Leitura, Linguagem, Aritmética, Noções práticas de Geometria, Ciências Sociais, Ciências Naturais, Instrução Moral e Cívica, Desenho, Caligrafia, Canto Orfeônico e Educação Física, e será distribuído em 5 anos nos grupos escolares da Capital e do interior, nas Escolas Reunidas, podendo ser incluído o aprendizado dos ofícios mais comuns, especializados ás zonas onde estiverem localizados.

Em relação aos recursos, consta no Regimento Fiscal Municipal, fruto do decreto, $n^{\circ} 1.601$ de 11 de março de 1935, no seu Art. 347, a seguinte aplicação para o sistema de ensino, 'a prefeitura aplicará nunca menos de dez por cento de sua renda, resultante de impostos, na manutenção e no desenvolvimento dos systemas educativos', (Governo do Estado do Pará, 1935, p. 57).

O funcionamento dos estabelecimentos de ensino foi garantido com abertura de uma linha de crédito especial para pagamento de professores na capital.

Art. $1^{\mathrm{o}}$ - Fica aberto o crédito especial de trinta e oito mil e quatrocentos cruzeiros $(\mathrm{Cr} \$ 38.400,00)$ destinado ao pagamento de quinze professores contratados para regência de escolas noturnas da capital, no corrente exercício. (GOVERNO DO ESTADO DO PARÁ, 1944, p. 01).

E outra linha especial para cobertura da merenda escolar.

Decreto-Lei $\mathrm{n}^{\circ} 453$ de 8 de maio de 1944.

Art. $1^{\circ}$ - Fica instituída a 'Merenda Escolar,' subordinada a diretoria de Educação e Cultura, sob a imediata organização e direção das diretoras dos grupos e escolas públicas do Estado e orientação científica do Serviço Médico Escolar.

Art. $2^{\circ}$ - Fica aberto o crédito especial de trezentos mil cruzeiros $(\mathrm{Cr} \$$ $300.000,00)$, para ocorrer, no presente exercício, as despesas de instalação e manutenção da 'merenda Escolar' nos educandários do governo. (GOVERNO DO ESTADO DO PARÁ, 1944, p. 79).

As fontes mostram que no orçamento da Prefeitura de Belém, a rubrica para a instrução pública foi aprovada pela prefeitura, pela última vez em 1936, para o exercício de 1937, primeiro ano de vigência do Estado Novo.

PMB

Lei ${ }^{\circ} 09$ de 23 de dezembro de 1936

Orça a receita e fixa a despesa para o município de Belém para o exercício de 1937. 
A Câmara Municipal de Belém estatui e eu sanciono e publico a seguinte lei:

\section{Título I}

Art. $1^{\circ}$ - O orçamento do Município de Belém para o exercício de 1937, estima a receita em 8.731:000\$000 e fixa a despesa em 8.730:790\$000.

Título II

Art. $\mathrm{n}^{\circ} 11$ - A despesa do Município de Belém, fixada em 8.730:790\$000, será effectuada através das seguintes verbas:

(...)

$\S n^{\circ} 19^{\circ}$ - Serviço de Educação e saúde pública.

a) Quota destinada ao serviço de Educação e saúde pública, na forma do art. 156, da constituição federal e $\S \mathrm{n}^{\circ} 02$, art. 74. da Constituição do Estado............771.000\$000.(GOVERNO DO ESTADO DO PARÁ, 1937, p. 3 - 73 - 77.)

Em relação às décadas de 1920 e início de 1930, a lei não especificava como as prefeituras deveriam proceder com os recursos, o que subtende a tutela do Estado para com o ensino.

Em 1944, quando da reformulação do Regimento do Ensino Primário, as escolas foram classificadas pela denominação entrancia, segundo a qual eram estabelecidos os salários dos servidores:

Art. 66 - Para os efeitos de provimento e de fixação de vencimentos, serão as escolas assim classificadas:

Primeira entrancia: escolas isoladas localizadas no interior dos municípios, fóra da das sedes dos mesmos.

Segunda entrancia: Grupos escolares e Escolas Reunidas do interior, escolas isoladas de sedes dos municípios e orfanato "Antonio Lemos."

Terceira entrancia: Escolas do Instituto "Gentil Bittencourt," Grupos

Escolares e Escolas Reunidas da Capital. (GOVERNO DO ESTADO DO PARÁ, 1944, p. 75).

No mesmo regimento o Estado como principal provedor e elaborador das políticas públicas paraenses, ao classificar as escolas estaduais para provimento de salários, torna-se omisso em relação às escolas de ensino primário municipal, não as classifica para efeitos de provimentos de salários, 'Art. 67 - Asescolas auxiliares municipais, noturnas e dos internatos primários no Interior, ou de alfabetização não são consideradas de entrancia, para efeito de provimento' (GOVERNO DO ESTADO DO PARÁ, 1944, p. 75).

No ano de 1944, o Estado regulamenta as escolas aptas para ministrarem o ensino primário. Segundo o art. 42, do Regimento do Ensino Primário, os estabelecimentos eram:

-.Nos cursos de jardim da infância;

-.Nos grupos escolares;

-.No Instituto Gentil Bittencourt;

- No Orfanato "Antonio Lemos";

- No Instituto Lauro Sodré;

- Nas escolas reunidas, isoladas e auxiliares;

- Nas escolas noturnas; 
- No curso especial para débeis e retardados pedagógicos;

- Nas escolas municipais; e

Nos internatos primários do interior.

Por esta estruturação percebe-se a existência das escolas municipais,aspecto esse que contribui para a organização do ensino primário de Belém do Pará, ainda que a mesma fosse desprovida de um arcabouço normativo próprio

O reforço a essa organização é percebida em muitos outros artigos desse mesmo Regimento. No art. 64, está expresso que "as escolas municipais só funcionarão com uma matrícula de 15 a 30 alunos e serão sempre mistas". (Governo do Estado do Pará, 1944, p. 74); no art. 63, estabelece o sexo para poder exercer a profissão de magistério nas referidas escolas, "as escolas mistas só poderão ser regidas por professoras". (Governo do Estado do Pará, (1944). Apud. Rosário,(1998. p. 99)

A inclusão do ensino primário municipal na estruturação da rede de ensino do Pará, bem as normatizações advindas do Regimento do Ensino Primário, fortaleciam a idéia de criação de um órgão independente para o ensino primário de Belém do Pará. Entretanto, o ensino continuava sobre as diretrizes da Secretaria de Estado de Educação e Saúde Pública, criada em 1930, por Magalhães Barata.

Por outro lado, verificamos que, além da interferência do governo do estado nos rumos da organização do ensino primário, seja do ponto de vista financeiro, organizacional e principalmente de autonomia, esse mesmo governo encampava escolas municipais.

Art. $\mathrm{n}^{\circ} 1^{\circ}$ - Ficam encampadas, pelo Estado, as escolas ' 13 de maio' e 'Alcindo Cancela', mantidas pela prefeitura municipal de Belém.

Art. $n^{\circ} 2^{\circ}$ - As professoras que estavam na regência das referidas escolas perceberão os vencimentos de escolas isoladas dos subúrbios da capital 1a. entrancia. (Governo do Estado do Pará, 1944, Apud. Rosário (1998. p 103).

O Interventor ao encampar as escolas municipais, delineava suas ações para fortalecer ainda mais a educação a cargo do governo estadual deixando a organização do ensino primário de Belém do Pará fragilizada, uma vez que, saía de sua esfera político/pedagógica, duas importantes escolas com as quais poderia encabeçar a política educacional do município.

Neste sentido, a organização estadual fortalecia-se, e por conseguinte a figura do próprio interventor.

Essa preocupação para com o encaminhamento da organização do ensino primário aparece explicitamente, nesse mesmo ano, por meio do Regulamento do Ensino Primário, no qual o governo define os critérios de criação de escolas.

Art. 45 - Na capital, nas sedes de municípios e nas localidades em que for elevada a população escolar, o govêrno poderá criar grupos e escolas reunidas, preferindo para esse fim os municípios em que as respectivas prefeituras fornecerem ao Estado, de cooperação com o govêrno, prédios apropriados. (Governo do Estado do Pará, 1944. Apud. Rosário, 1998 p. 108). 
A análise dessa decisão leva-nos à seguinte indagação: se o governo do Estado podia criar tais escolas nas sedes dos municípios paraenses e na capital, Belém, desde que os prefeitos construíssem os prédios, há de perguntar: por quê não repassar essa responsabilidade para a esfera dos municípios?

A resposta encontra-se na própria natureza organização do ensino primário de Belém do Pará que durante a vigência do Estado Novo, constituiu-se em um elemento político/pedagógico importante no âmbito da educação pública do Estado do Pará, em que sua dimensão política foi trabalhada de maneira a não confrontar-se com o projeto do regime autoritário em curso.

Algumas normas estabelecidas pelo Regimento do Ensino Primário qualificam muito bem o período que se vivia, ou seja, um período ditatorial. Mas que ao mesmo tempo, voltava-se para o aprofundamento das mudanças sociais, exacerbando o sentimento de nacionalismo nas pessoas. A organização do ensino por meio da escola foi chamada para fazer coro a esta linha. Assim, o Regulamento do Ensino Primário, previa nas escolas a obrigatoriedade do canto dos hinos Nacional e da Bandeira:

$\S 2^{\circ}$ Os trabalhos escolares, em todos os estabelecimentos de ensino, serão iniciados com canticos em côro, obrigatoriamente, dos hinos Nacional e da Bandeira, devendo o professor de cada classe ou escola dar aos seus alunos uma explicação prévia da letra dos mesmos, uma vez por semana, e acompanhá-los nos canticos, a começar um mês depois do início das aulas. (GOVERNO DO ESTADO DO PARÁ, 1944, p. 84).

As fontes demonstram que o aprendizado do hino nas escolas significava, sobretudo, a certeza de que o futuro do país, através dos jovens e das crianças, seguiria a linha, reforçada pela ditadura de Getúlio Vargas, de mudança nas organizações sociais, no nacionalismo e desenvolvimentismo, bem como serviu para a produção de uma nova mentalidade.

Substituíndos as luctas políticas pelas actividades economicas e os partidos de administração racionalisada no sentido de corresponder às necessidades públicas - o Estado Novo guardou como segredo do seu milagre o respeito pela tradição. Regimem revolucionário para transformar a condição precária do homem e do povo , educando, saneando e disciplinando: revolução evolucionista, única se pode realisar com a outorga de um estatuto político sem o motim, sem o combate, sem o clamor, porque feita e conduzida pela serenidade pelo respeito, fixando a vida nacional com a realidade da sua prática e o reconhecimento das suas exigências . Ao corpo extenuado pelas luctas estereis, odios e divergências, energias novas e sadias vieram, nas leis operarias, agrarias, nacionalização, de assistência e beneficentes, dar um sôpro de vida e de alegria, de conforto e de esperança.

Renasceu a confiança do povo no seu governo. O trato directo entre elles, extincta a intermediação dos partidos, faz com que se conheçam e entendam melhor. $\mathrm{O}$ interesse nacional sobrepairou a todos os demais; as necessidades de ordem geral passaram a compreender individuaes e aquella igualdade pregoada pela democracia liberal e jamais realisada eficazmente, está sendo attendida na vigencia de nossa democracia nitidamente social. (GOVERNO DO ESTADO DO PARÁ, 1940, p. 04). 
Essa perspectiva é observada no art. 83 do Regimento do Ensino Primário, que trata das incumbências dos professores, no parágrafo $2^{\circ}$, estabelece: 'inspirar aos alunos bons sentimentos, incutir-lhes no espirito, por meio de exemplos e das lições ocasionais, o culto da Pátria'; no parágrafo 24: 'fazer palestras cívicas a seus alunos em linguagem acessível ao menos nas vésperas dos feriados nacionais alusivos aos fatos comemorados na data,' e no parágrafo $25^{\circ}$ 'acompanhar seus alunos ás festas cívicas promovidas pelo govêrno’. (GOVERNO DO ESTADO DO PARÁ, 1944, p. 77-79)

Nessas incumbências está incutida a premissa do trabalho em direção ao nacionalismo e desenvolvimento do país. É o que mostra o discurso de Deodoro de Mendonça, Secretário Geral do Estado quando da visita de Vargas à Belém.

O problema social continuando o desenvolvimento, atinge os extremos de sua conquista, recebendo as classes trabalhadoras da revolução legal brasileira, concessões espontâneas que não permitiram sequer movimentos ou agitações das massas. O que ali afora é obtida a custa de greves e tumultos, sangue e depredações, o Brasil concede prodigamente como acto normal de seu adeantamento político e social. As organizações syndicaes, como as grandes leis do salário mínimo, do seguro colletivo, das férias, dos accidentes, das juntas de conciliação, da justiça do trabalho - compondo as relações entre empregadores e empregados, entre capital e o braço, sem tirar daquelle as garantias, mas creando para este um padrão digno de vida e de actividade, valorizando o homem e sua capacidade - outorgam ao Brasil um lugar excepcional entre os povos modernos e deram às nossas massas proletárias um conceito de ordem e de disciplina, que as colocou diversas das suas congeneres de outros paizes, como elementos de segurança, como colunas conscientes de força a cooperarem para a defesa do Estado e da auctoridade sempre que se faz mistér. (GOVERNO DO ESTADO DO PARÁ, 1940, p. 05).

A questão do nacionalismo ${ }^{8}$ foi também ressaltada no início do Estado Novo no discurso do Diretor da Educação e Cultura, quando da visita de Getúlio Vargas a Belém, durante o governo Malcher:

Exmo. snr. Presidente:

Ainda há pouco, teve v.ex. a oportunidade de ver a mocidade escolar de Belém, empunhandoaBandeiraNacional, fremente de entusiasmo, desfilar, ao som das bandas marciais dominada pela vontade única de saudar v.ex. e demonstrar o quanto seu nome é querido e admirado pela geração que se está formando e que espera da alta visão e descortino político de que v. ex. é tão felizmente dotado. (GOVERNO DO ESTADO DO PARÁ, 1940, p. 32). (grifos nossos).

Além disso, o poder político, por meio da portaria de 5 de julho de 1943, determinou como se dariam as substituições de professores, ou seja, as substituições também passavam pelo filtro do governo estadual, através de seu Departamento de Educação.

Essa medida fez com que os referidos professores ficassem à mercê dos ditames do governo do estado, ou seja, a manutenção dos servidores públicos sob o controle do Estado. 
O interventor federal, no Estado do Pará, usando de suas atribuições que lhe são conferidas:

\section{RESOLVE:}

Determinar ao Diretor Geral do Departamento de Educação e Cultura, que todas as substituições de professores de grupos escolares da capital, verificadas a partir desta data, serão preenchidas pela adjuntas interinas exoneradas por decreto de $1^{\circ}$ de julho do corrente ano.Cumpra-se e publique-se. (GOVERNO DO ESTADO DO PARÁ, 1940, p. 6).

fiscalização controle, estabelece:

E numa tentativa clara de manter todas as escolas sob sua estreita

\section{DECRETA:}

Todos os estabelecimentos de ensino primário, públicos e particulares, ficam obrigados a adotar livros de escrituração de matrícula e frequiência, de acordo com o modelo oficial e na forma estabelecida pelo Convênio Estatístico. (GOVERNO DO ESTADO DO PARÁ, 1940, p. 20).

Essas injunções político/pedagógicas entre a organização do ensino primário e as ações do governo estadual, representadas pela Secretaria Estadual de Educação, decorrem do entendimento de que as elaborações e aplicações de políticas educacionais e seus resultados são decisivos na construção histórica da prática social e do pensamento educacional, em um determinado contexto.

\section{Considerações finais}

As fontes históricas sobre a organização do ensino primário de Belém do Pará, durante o Estado Novo, demonstram que esta foi forjada e confundida com a organização da educação sob a responsabilidade do governo estadual, porque, dentre outros motivos, na década de 1930 e mais da metade dos nos 1940 não existia órgão responsável pela educação municipal. Coisa que só passa a ser constituída depois do Estado Novo, em 1949, com a criação da primeira Diretoria de Ensino Municipal.

A história dessa organização carrega em si certa singularidade,pois, ainda que dependesse das diretrizes traçadas fora do âmbito de sua atuação, deixou seu legado educacional para as futuras gerações. Porém nesse legado observa-se as marcas da obediência ao governo central por meio do governo estadual como um importante aspecto a ser considerado em qualquer análise. Há de se reconhecer, porém que propostas acenadas de fora para dentro, não são particularidades do Estado Novo. Desde o início do século, o país experimentava processos de rupturas/continuidades, que afetavam, alterando, as organizações sociais brasileiras, entre elas as educacionais. Como os municípios, ao longo de suas histórias, até a década de 1980, prescindiam de organização própria, acabavam por produzir o processo educativo sob suas responsabilidades apenas nos vácuos deixados pelos outros sistemas estadual e federal.

Essa perspectiva pode ser inferida a partir das ações que foram empreendidas pelos gestores municipais em relação à organização da educação desde a implantação do primeiro governo provisório após a revolução de 1930 até 1949, quando foi criado o primeiro órgão oficial de instrução pública - Diretoria de Ensino Municipal, 
através da lei $\mathrm{n}^{\circ} 503$ de 27 de maio, implicando no fortalecimento e na organização do ensino sob responsabilidade do executivo municipal.

Em sua conclusão preliminar aponta o ensino primário de Belém, no período, como um instrumento importante de barganha política e que ao mesmo tempo passava por um processo de redirecionamento histórico-político-social no qual os poderes políticos estadual e municipal figuravam como atores principais no papel de mediadores e elaboradores das propostas pertinentes à educação

\section{REFERÊNCIAS BIBLIOGRAFICAS}

CARnEIRO, J. Q. O Pessedismo e o Baratismo no Pará. São Paulo, 1991, 209p. Dissertação (M.S.) - Universidade Estadual de Campinas-UNICAMP.

DAMASCENO, R. A. A Segunda República e a Educação no Pará: Um olhar sobre o dominante, Centro de Educação - UFPA. (mimeografado), 1993.

DIÁRIO DO ESTADO DO PARÁ. quinta - feira, 01/02/40, Belém - PA., 1940

FAUSTO, B. A Revolução de 30. São Paulo: Brasiliense, 1970.

FERNANDES, F. A Revolução Burguesa no Brasil: Ensaio de Interpretação Sociológica. Rio de Janeiro: 3. ed. Guanabara, 1987.

FISCHER,T. Poder Local: Governo Local e Cidadania. Rio de Janeiro: Fundação Getúlio Vargas, 1993.

GOVERNO DO ESTADO DO PARÁ. Mensagem apresentada a Assembléia Constituinte do estado, em 14 de abril de 1935, Belém: Gráfica do Instituto D. Macêdo Costa, 1935.

GOVERNO DO ESTADO DO PARÁ. Lei no 09/36. Belém: TYP do Instituto Lauro Sodré, 1937.

GOVERNO DO ESTADO DO PARÁ. Coleção de decretos. Belém: Oficinas gráficas do Instituto Lauro Sodré, 1940.

GOVERNO DO ESTADO DO PARÁ. Coleção de decretos e portarias, Belém: Oficinas gráficas do Instituto Lauro Sodré, 1944.

POMAR, P. CARVAlHO, L.M. Memórias no 2 Pedro Pomar. Debates, São Paulo: ed. Brasil, 1980.

POPKEWITZ, T. S. Reforma Educacional: uma política sociológica-poder e conhecimento em educação. Trad. B. A Neves. Porto Alegre: Artes Médicas, 1997.

PREFEITURA MUNICIPAL DE BELÉM. A Amazônia vai ressurgir. Belém: Serviço de Publicidade e Propaganda da PMB, 1940.

RODRIGUES, H. Álbum do Pará, Belém. 1939

ROSÁRIO, M J. A Organização da Educação do Município de Belém - PA. De 1937 a 1945. (Dissertação). Universidade Metodista de Piracicaba -UNIMEP. Piracicaba, São Paulo, 1998.

REIS, A. C. F. Síntese da história do Pará.Belém. 1942 
ROMÃO, J. E. GADOTTI, M. Município e Educação.São Paulo: Cortez, 1993.

SEVERINO, A. J. ; GATTI, B. A.; OLIVEIRA, B. A. Demerval Saviani e a educação brasileira: O simpósio de Marília. São Paulo: Cortez, 1994.

SCHWARTZMAN, S. COSTA, V. M. R. BOMENY, H. M. B. Tempos de Capanema. Rio de Janeiro: Paz e Terra; São Paulo: EDUSP, 1984.

VEIGA, H. M. A Redemocratização em Belém (1945-1947): Os comitês democráticos e a Campanha Contra a Fome. Belém: FASE, 1984.

Notas

${ }^{1}$ Este artigo foi apresentado no Encontro, "Sociedade, História e Educação no Brasil", ocorrido em Campinas -SP, em 2007, acrescido das sugestões dos.participantes do GT e das pesquisas empreendidas pela equipe do HISTEDBR/Secção-PA, entre 2008 e 2010.

${ }^{2}$ Deodoro de Mendonça influente político, é assim caracterizado Emmi (1988), citada por Mello (1988) em Damasceno (1993, p. 8). "Na década de 20, com os 'lauristas' no poder, intensificou-se a formação de latifúndios em várias regiões do Estado. No caso de Marabá, a dominação política era exercida pelo comerciante da castanha e secretario de governo, Deodoro de Mendonça, e sua parentela. Este apareceu no cenário político estadual no segundo governo Sodré (1917-1921) e utilizou-se da máquina administrativa pública para solidificar sua posição econômica. Segundo a autora, ele utilizava-se de sua influência no interior do Partido Republicano Federal para, em benefício próprio, mesmo que agindo contra correligionários, assumir o controle da máquina estatal e garantir a consolidação de seu poder em Marabá, colocando parentes (são citados 13) em postos chaves. Com a mudança de governo em 30 e a ascensão de Barata ao poder - tendo o Pl [Partido Liberal] como expressão - o jogo político entre as oligarquias da castanha se altera (...). Deodoro perde espaço para correntes mais afinadas com o baratismo.".Deodoro de Mendonça retorna ao cargo no segundo governo de José Malcher (filho do primeiro Malcher).

${ }^{3}$ Essas paixões referiam-se ao medo do implante do comunismo aos moldes da União Soviética, por intermédio do PCB.

${ }^{4}$ Durante a vigência do Estado Novo, os prefeitos de Belém foram: Alcindo Cacela (1935 até 31/12/37); Abelardo Condurú (de 03/01/38 a 07/03/39; Orlando Moraes (15/03/39 a 17/06/39); Abelardo Condurú (23/06/39 a 10/02/43); Jerômino de Calvacante (20/02/43 a 01/03/43); João Casanova L. e Silva (02/03/43 a 02/12/43 - interino ); Jerônimo de Calvacante (03/04/43 a 02/07/43);Otávio Augusto B. Meira ( 09/07/43 a 02/12/43 - era interino e se torna prefeito); Alberto Engelhard (28/12/43 a 06/11/45) e Augusto Serra $(07 / 11 / 45$ a 09/02/46).

${ }^{5}$ Abelardo Leão Condurú, teve forte atuação na política paraense, sua carreira teve início quando o então candidato a presidência da República, visitou Belém, e Abelardo o saudou com um discurso público. Ainda na República Velha, combateu ao lados dos revolucionários de 30. Depois da vitória, apoiou Magalhães Barata, sendo por ele nomeado prefeito de Belém, em 1935. Rompeu nesse mesmo ano, e juntou-se aos dissidentes, filiando-se na Frente Única paraense. No Estado Novo, o interventor Malcher, nomeou-o mais uma vez prefeito de Belém, só saindo para ocupar uma das diretorias do recém-casado Banco da Borracha (hoje Banco da Amazônia S/A - BASA). Em 1946, ingressou no Partido Social Progressista, participando das lutas pela democracia, no entanto rompeu com o líder do movimento general Assunção por não nomeá-lo prefeito de Belém, pela terceira vez. (cf, Rocque, 1972)

${ }^{6}$ A Universidade Federal do Pará foi criada em 1957.

${ }^{7} \mathrm{O}$ primeiro Regimento do Ensino Primário foi regulamentado, na primeira interventoria de Magalhães Barata, em 1931.

${ }^{8}$ Sobre essa questão do nacionalismo consultar: Schawartzman (1984).

Recebido em: 19/07/2011

Aprovado em: $\quad 25 / 07 / 2011$ 